\title{
Global Health and Global Health Ethics
}

\section{EDITED Ey Solomon Benatar and Gillian Brock}

Comanimar

Medicine

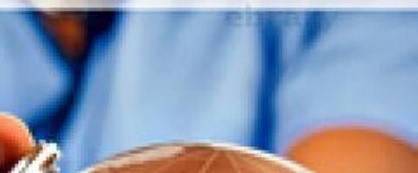

\section{CAMmRIDGE www.cambridge.org/9780521146777}

. Global Health and Global Health Ethics.

: Cambridge University Press, . p 1

http://site.ebrary.com/id/10442841?ppg=1

Copyright (C) Cambridge University Press. . All rights reserved. May not be reproduced in any form without permission from the publisher, except fair uses permitted under U.S. or applicable copyright law. 


\author{
Kearsley A. Stewart, Gerald T. Keusch and Arthur Kleinman
}

\section{Introduction}

Over the past several decades, political conflicts, economic volatility and large-scale cultural and social changes have strongly influenced not only global health problem and solution frameworks, but the very way we conceive of global health as a public good. As politicians, business people and cultural elites employ the language of global health to shape discourse and policies focused on displaced and migratory peoples, they have perhaps unwittingly broadened the classic public health agenda. As a consequence, that agenda now includes violence and its traumatic consequences, the health (and mental health) impact of natural and social catastrophes, other health-related problems from obesity to substance abuse, and the effect of pharmaceutical and digital technology innovations not previously considered to be core public health issues. They expand and reformulate the traditional spheres of public health, and challenge classic public health values.

As a result, debates shaping global health research, ethics, policy and programs have developed along two parallel tracks. One can be characterized as a neoliberal approach combining economics (liberalization of trade and financing; new mechanisms for product development for diseases of poverty involving public-private partnerships; cost-effectiveness analysis), disease-specific and biotechnology programs and security concerns. The other has focused on human rights, social justice and equity frameworks with a broader, more inclusive model of the determinants of health. This perspective calls for a transformation of the current fractured system of global health governance into a transparent and accountable system, better equipped to address the world's global health agendas. It embraces public health as one of the essential features of a new moral commitment to remake the world, similar to the environmental/climate change movement. In fact, in 2002, the American Public Health Association explicitly affirmed in their professional code of ethics, Principles of the Ethical Practice of Public Health, that the pursuit of public health is an "inherently moral" obligation (APHA, 2002).

Very recently, the two approaches appear to be converging around a values focus to bolster arguments in favor of increased resource allocation for global health programs. Byvalues, we mean the set of expressed qualities that guide behavior, for example, honesty, compassion, generosity, empathy, tolerance. What is new is an emerging recognition that the "social context" of values must be explored before we can begin to understand the meaning of any value, whether personal, political or invoked directly in reference to global health. This is so because values, while expressed as individual behaviors, are often rooted in cultural interests or shaped by accepted norms that can appear to be so natural as to be invisible. At times, closely related values may be in conflict. For example, within the notion of justice as fairness there are values such as equity, need, merit, solidarity, social worth and freedom, each of which could lie at the heart of a particular and somewhat distinctive theory of justice. Values are also so central to political life that policy makers freely admit that political discourse that appropriates values talk builds political support, consequently driving policy goals. The result is that values may be neither consistently applied nor shared across diverse policy sectors. Important global health policies and programs need the underpinning of values, broadly and deeply embedded, specifically to bolster arguments for increased resource allocation. These values can be hidden, in plain view in mission statements or remain unexamined. Where is the values debate in global health headed and what can public health, the social sciences and the humanities contribute to shaping and amplifying the discussion?

An earlier version of this work has appeared: Stewart, K. A., Kleinman, A. \& Keuseh, G. T. (2010). Introduction: values and moral experiences in global health: bridging the local and the global. Global Public Health 5, 115-121. 


\section{Background}

To address this issue, the authors jointly convened a workshop entitled, "Values and moral experiences in global health: bridging the local and the global." Drawing on an interdisciplinary and international group of scholars and practitioners, the workshop explored the emerging values discourse as it relates to global health priority-setting, policy, governance, practice and research. An innovative approach was to form working groups after the workshop in order to reflect new thinking on the subject informed by the debates and discussions at the workshop. The collection of papers recently appeared in a special issue of Global Public Health (Stewart et al., 2010) and explore a variety of questions: What values are deeply embedded in the most important global health policies and programs? How do we combine moral philosophy, applied (empirical) bioethics, economics and public health and engage people in high-income countries to work to improve the health of people in resourcepoor settings? How could we change this engagement from a charitable/humanitarian value to a fundamental shared value that could withstand the inevitable periodic global economic downturns or perhaps even prevent these? How do we balance multiple, often personalized values to find consensus for setting priorities in global health policy and research agendas? How do we translate insights from highly specific, local cultural contexts into theoretical frameworks for effective global health governance that could transcend local boundaries? What is the relevance of political, ethical and economic theories to global health governance or offered assessments, of specific global-acting entities, such as the UN agencies, World Bank and the World Health Organization?

\section{Values and moral experiences in global health governance}

Values are situated in two spheres: first, actual moral experiences of people in their local worlds whose practices regarding what really matters can, and often do, diverge from their ethical aspirations; and second, more disciplined professional articulations of ethical responsibilities. By ethics we mean aspirations for and deliberations about universal values such as justice, the good, etc. In contrast, we use the word moral to refer to actual local practices that demonstrate values that are partisan, self-interested and not necessarily "ethical." More recently, practicing public health professionals have drawn upon liberation theology and social justice frameworks to raise awareness and financial support for global health initiatives. For example, Paul Farmer and Jim Kim in their work in Haiti, Peru and Rwanda, clearly recognize the connection between political structures and health inequities and therefore focus their efforts on political will to improve health. Others, like former US Senator and physician Bill Frist, use evangelicalism to attempt to reduce health inequalities through the ideology of individual responsibility and sheer determination. Feierman et al. (2010) have addressed the implication for global health of values animated by individual and local commitment but routinized by institutionalization through macro-level health policies.

Whereas values are deeply embedded in the most important global health policies and programs, even when the dialog is highly pragmatic or political, there is little understanding of how values function as important rhetorical devices for global health decision makers. It is evident that values are neither consistently applied nor shared across the diverse policy sectors of the players in global health. Who should shape and influence so-called international values? For example, what were the deep value commitments of Halfdan Mahler in 1979, when, as the secretary general of the United Nations at Alma Ata, he pressed for an emphasis on primary health care and an institutional commitment to Health for all by the Year 2000? His Scandinavian origins and familiarity with the social democratic welfare state clearly influenced his emphasis on health and social equity. But did the deeper values of his Lutheran religious traditions or his own personal biography transform an idea into a commitment? Many public health policy makers today seem comfortable with the idea of a "right to health care," but less comfortable with the idea of a "right to health." Amongst those who have made the commitment to a right to health, to what extent is it liberation theology, commitment to religious values or philosophical notions of distributive justice that undergird their passions for the human rights and health domain?

We posed several questions to be addressed by the workshop participants: Do values change as a result of an unfolding developmental process in global health? What conflicts in values exist between program donors at the global level and recipients at the local level? How are these conflicts resolved? Who decides? Do we need consensus? If so, to what degree? 
What should happen when these values, that shape global intervention, conflict with the local values of the intended beneficiaries of global health programs? No clear pathway exists to address or resolve these conflicts. How do we manage a plurality of values, especially in the context of the new public-private partnership paradigm for funding global health initiatives? How do we bridge local moral experiences with global health policies?

In response, Benatar et al. (2010) and Yang et al. (2010) contend that global health programs have failed to deliver better primary health care in resource-poor countries for three central reasons: a vertical rather than a combined vertical-horizontal system to reducing disease; a traditional disease-control model that focuses on preventing or treating individual illness while ignoring the broader social and cultural determinants of health; and the increasing inequity in access to basic health resources that are often available only to those who can afford them. Benatar et al. (2010) have argued that existing values in global health reflect the growth of global capitalism and a narrow commitment to scientific solutions delivered through large-scale programs. Therefore they advocate a new set of values that emphasize sustainability and global distributive justice. Yang et al. (2010) have offered an original analysis of the concept of sustainability in global health, arguing that the current donor-driven approach will never reach sustainability because the resulting narrow focus on disease control, combined with inconsistent funding, can have the paradoxical effect of sustaining the disease itself, rather than developing the broader assets and capabilities essential to preventing future outbreaks. They believe major opportunities exist right now to provide the right health services at the right prices where they are needed most.

\section{Ethics and priority-setting in the governance of global health research}

Awareness of the ethical challenges of conducting global health research in resource-poor settings emerged most famously in 1997 with the controversy over the use of a placebo-controlled study design in a clinical intervention to prevent perinatal HIV transmission in developing countries (Angell, 1997). The controversy sparked a decade of debate and research by bioethicists, public health practitioners, biomedical researchers and social scientists that focused primarily on the technicalities of health research study design, the compliance in resource-poor settings with international research regulations, and the appropriateness of Western normative research ethics for health research in the developing world. Recently, the debate about global health research has moved beyond the technical and regulatory questions of study design to a reconsideration of health research itself as a means to achieve better health equity. In a 2002 paper, Benatar proposed engaging global health research ethics not only as a mechanism to improve health care, but as a means for promoting a broader approach to reducing global inequities. Noting that the public health tools to treat, and perhaps even to eradicate, TB have existed for decades, he argued that the persistence of TB is due to inadequate attention to the fundamental causes of poverty (Benatar, 2002). To remedy this, he suggests that global health research ethics demand not only a higher standard of care for research participants in resource-poor settings, but obligate the research sponsors to improve the health-care needs in the community as well (Shapiro \& Benatar, 2005).

However, this raises new questions: What constitutes a need? Who will define it? Who should prioritize it and based on what principles and values? Who will pay for it? What is the role of the humanities and social sciences in this emerging debate? Global health research is a collaborative, multisectoral and multidisciplinary effort; how can we move forward in this interdisciplinary endeavor when there are multiple sets of principles competing to define social value and determine how to achieve social justice through global health research? Do we describe the social value of global health research from an individual or aggregate (and which aggregate) level? Can we build principles based on a conglomerate of evidence and arguments from ethnographic, empirical and philosophical/theoretical data?

To respond to such questions, IJsselmuiden et al. (2010) have focused on the principles of global justice and solidarity to argue for a new era in the ethics of international health research. They insist that research must be more responsive to local health systems and strive to enhance local capacity through equitable collaboration. Thus, they envision new approaches in the research review process to prompt funders from the North to consider the inclusion of local priorities as a condition for funding. Finally, they argue that researchers have an obligation to conduct research promoting health equity and linking results with future local development. In contrast, Stewart \& Sewankambo (2010) 
have considered the process of global health research itself as a socially embedded activity. Their analysis of therapeutic misconception reveals that local expectations of research benefits are infinitely more complex than previously thought, while motivations for participating in research suggest an intricate calculus of responsibilities between researcher, participant and community. By studying the cultural value and social impact of global health research from the lived experience of the research participant, rather than from the operational perspective of the researchers, a more meaningful understanding of the social value of global health research should emerge.

\section{Economic valuations in global health governance}

Measurement is a core concern for economists, and so it is natural for economists to strive to measure the value of health in the context of economic theory. One way for this, whether on a national or global scale, is to assess the value of health in financial terms (the generation of wealth measured as Gross Domestic Product or GDP). A second measure to assess the value of an individual's health at the individual level is to calculate their total projected lifetime earning, which contrasts to assigning a cost to the extension of healthy years of life and the reduction of years lived with disability due to ill-health. A third approach to measuring the value of health recognizes that health status might be defined, acted on, rejected or narrated in quite distinct ways. For example, as an abstract normative principle in times of non-crisis, as a more "objective" or concrete assessment in times of crisis, or as a moral tale, explanation or regret when reflecting on or narrating the event. Moral positions on violence and trauma are often experienced in this manner. Yet however we assign value to health, we must find common ground for answering basic questions of assessing value in global health. To begin with, how do we measure the value of health and how do we scale it? How is new healthrelated value created and distributed? We suggest that by connecting the analytics of an economic model of evaluating health with the advocacy efforts of a social justice approach, the effort to measure value in the creation of global health programs will contribute to better outcomes in the implementation of those programs.

The international development community has elevated health as a central concern since the publication of the 1993 World Development Report, Investing in
Health (World Bank, 1993). This report not only documented the importance of healthy populations in the creation of wealth, but also determined that the generation of new knowledge through health research was an essential factor. This has led to many initiatives from global intergovernmental institutions, bilateral assistance agencies, foundations and charities, religious and secular, that link programmatic interventions to knowledge generated largely through external support, both financial and intellectual. Investment in health research in high- and many middle-income countries which can afford the costs, has improved. The predominant investment has been on research on the problems of these more economically developed societies, characterized by the Global Forum for Health Research (GFHR) as the $10 / 90$ gap, the reality that $90 \%$ of investments are directed towards the health problems of $10 \%$ of the world's population.

McGahan \& Keusch (2010) have argued that the concept of value or valuations in economics represents something different than the concept of value in global health advocacy. For example, we have the knowledge and technology to prevent or treat most diseases, however those with the greatest need have the least access. This is the consequence of the interplay between the moral content we assign to equitable access to health resources and the reality of shortages in local healthcare markets. Markets, the most common way of assigning value, fail to address these inequities, indicated by the inability of the 1994 Trade Related Aspects of Intellectual Property Rights (TRIPS) Agreement of the World Trade Organization (WTO) to significantly improve pharmaceutical innovation for diseases of the poor. They note there are several mechanisms to assign market value to health and the importance of the market mechanism for improving local access to health-care resources (McGahan \& Keusch, 2010). However, the imperative is to use the method of economic valuation best suited to stimulating product and service development, and to insist on the relevance of the global public good perspective, if there is to be a real chance to reduce scarcity at the local level.

\section{Anthropology as a bridge between the local and the global in global health}

An empirically based ethnographic approach may be the best way to effectively bridge local narratives of health with the cosmopolitan global health values that shape macro-level health policies. Transparency 
and accountability have emerged as key values in the formulation and implementation of global health policy, necessitating a more direct and intimate relationship between those who control global health assets and those whose lives are shaped by the distribution of resources. For instance, the development of community advisory boards to act as translators between the language of research protocols and the idioms that resonate with the community and relay local concerns back to investigators. While this may facilitate more efficient and effective health research, it also raises local expectations of the power of community opinions to influence globally financed health interventions. This local-global interface can be a litmus test of the true worth of transparency and accountability as essential values for the funders and practitioners of global health. Feierman et al. (2010) consider the production of contextualized ethnographic knowledge about local experiences of global health programs (kinship, technologies, sources of power and authority) to be critical to the success of those programs. Equally important, but often overlooked, is how the new content and knowledge moves or "flows" amongst global health actors and defines the contours of the local-global interface. More than a lack of ethnographic description and analysis, the absence of a deep understanding of social action at all levels in the practice of global health is a serious barrier to effective program implementation at the local level (Feierman et al., 2010).

A recent example of the unique value of empirically based anthropology to resolve a serious problem between a local community and a global intervention is the re-emergence of wild polio virus in northern Nigeria in 2003. Between 1988 and 2002, the WHO Global Polio Eradication Initiative, the world's single largest, internationally coordinated public health project, reduced the number of cases of wild polio virus worldwide by $99 \%$. However, in August 2003, three states in northern Nigeria suspended polio immunization campaigns, following concerns by some public figures regarding the safety of the polio vaccine. Local political and religious leaders, and even physicians, called on parents to refuse the polio vaccine for their children. They accused western countries of deliberately contaminating the vaccine with anti-fertility agents, HIV, and/or cancer cells in a plot to sterilize or sicken African children, particularly Muslim children. Subsequently, a new outbreak occurred, originating in the northern state of Kano, re-infecting previously polio-free areas within Nigeria (including Lagos) and eight previously polio-free countries across west and central Africa. As a result, for the first time since efforts to eradicate polio began, more countries suffered polio cases in 2003 due to importations than were themselves endemic for the disease. Resolution was achieved in July 2004 through dialog after the WHO and UNICEF consented to allow the vaccine to be tested in a Muslim country (Indonesia) with new suppliers of polio vaccine from Biopharma, an Indonesian company. Within 12 months, polio eradication campaigns resumed across northern Nigeria in July 2004. However, Nigeria continues to report wild polio virus. In 2006, 1124 cases were identified in Nigeria, accounting for well over two-thirds of the total number of cases worldwide. Wild polio virus, as well as cases of vaccinerelated polio, continue to plague northern Nigeria as recently as mid 2009.

Local anxieties about the 2003 polio campaign in Nigeria reflect a difficult history of externally supervised public health projects. It is widely believed that the deaths of five children enrolled in a 1996 research study in northern Nigeria were caused by the unethical use of Trovafloxacin (Trovan), an antibiotic produced by Pfizer to combat meningitis. Even before this tragedy, aggressive anti-fertility campaigns sponsored by the southern-dominated Nigerian government in the 1980s generated mistrust of the public health system in the northern areas of the country. The significance of these facts was grossly underestimated by the implementers of the Kick Polio out of Africa campaign. However, anthropological analysis offers a clearer assessment of why parents refused an effective lifesaving public health intervention while public health ethics outlines a more responsive, and ultimately effective, approach to mass vaccination conducted in an atmosphere of fear and mistrust. Several anthropologists cautioned that local suspicion of the polio eradication campaign was rooted in the stark contrast between the well-organized and free delivery of the polio vaccine and the chronically under-funded and dysfunctional primary health-care system (Renne, 2006). Furthermore, from the perspective of the local community, more pressing health issues, such as malnutrition or malaria, were consistently ignored by public health officials. Even the 2003 Nigerian government report that confirmed the safety of the polio vaccine was rejected by the northern states because the local Muslim community did not participate in the production of the government report. The impasse was finally broken after the government and external 
health agencies consulted with the local communities and fresh testing of the polio vaccine was commissioned in Muslim-operated biomedical facilities in Muslim countries. One of the primary principles of ethical public health decision-making is a respect for autonomy and human dignity; this is the opposite of the paternalism demonstrated by both the Nigerian government and the international sponsors of the immunization campaign. Understanding local cultural norms is a cornerstone for effective collaboration between public health workers and community leaders and members. Anthropologists can help public health workers anticipate when health intervention protocols may be at odds with local sentiments, thus avoiding these tragic breakdowns of communication between the community and the public health sector.

\section{New approaches in global health practice}

Given the critical role of research and new knowledge generation for the improvement of health status, it is surprising that academic values (for example scientific integrity, consistency, measured judgment, curiosity, intuition, creativity and data-driven decision-making) are generally ignored in the complex governance of global health. However, new directions in global health practice are beginning to appear. Kim et al. (2010) believe that twenty-first centuryglobalhealth programs must shift from a series of individual, disease-centric programs to a coordinated system of fully-functioning health-care delivery programs. They describe the Harvard Global Health Delivery Project, a partnership between the Harvard Medical and Business Schools, as a strategic road map towards the creation of a systematic framework for innovation in the infrastructure of global care-delivery programs. Application of the core business value of profitability to the core global health value of maximizing health in resource-poor settings, offers the opportunity to address one of the greatest constraints in medicine today, the delivery of health care. Kim et al. (2010) consider it essential to foster more effective partnerships between academic institutions, NGOs, private entities and the public sector in order to deliver real value through the effective delivery of health care in resource-poor settings. Sharing a similar vision, a group of biomedical, business and social science researchers at Northwestern University are combining industry, donors and academia to narrow the gap between supply and demand for HIV/AIDS diagnostics (Palamountain et al., 2010). Universities are uniquely positioned to catalyze a new type of partnership between non-profit global health donors and commercial diagnostic companies, build on the efficiency and creativity of the private sector, reduce industry risk by guaranteeing a low-margin, high-volume financial opportunity and provide medical goods to resource-constrained populations. Universities are increasingly engaged in implementation programs on the ground in global health settings, and yet at the same time, provide the academic milieu to advance critical reflection on value issues. Hence, they are engaged with practice as well as with reflection on that practice. The third unique qualification of the university is its role in the education and shaping of the values of its students, who represent the future for all endeavors. No other institution can claim a serious engagement in all three domains of teaching, research and service as strongly as universities.

\section{Conclusion}

New initiatives in global health, like biomedicine itself, display a striking inadequacy to examine the meanings, experiences and practices that so significantly shape the nature of their governance. By developing a robust, multidisciplinary discourse on values, and in particular, by connecting the local and the global, we can better understand the sources, frameworks and larger implications of the governance of global health entities. Local worlds and local lives anchor anthropological accounts of sickness, care and prevention in resource-poor and resource-rich societies. Without this focus, no bridge can effectively connect large-scale policies and programs with real people struggling to find solutions to their health problems. Without this focus, unintended social consequences, as with inequality itself, will continue to undermine the effectiveness of global programs to reduce unequal access to health care. Equity and justice cannot be understood apart from local realities. Hence the local must be recognized as a core value in all global health efforts, equivalent to equity, justice and human rights. We assert that this new dialog must take place among the broad range of stakeholders and participants in the ongoing global health revolution, and that social scientists must have an equal seat at the table, to ensure that decision making can reflect the concerns of those most in need of improvements in health status. 


\section{References}

American Public Health Association (APHA) (2002). Principles of the Ethical Practice of Public Health, Version 2.2. Washington, DC: Public Health Leadership Society, APHA.

Angell, M. (1997). The ethics of clinical research in the Third World. New England Journal of Medicine 337, 847-849.

Benatar, S. R. (2002). Some reflections and recommendations on research ethics in developing countries. Social Science and Medicine 54(7), 1131-1141.

Benatar, S. R., Lister, G. \& Thacker, S. C. (2010). Values in global health governance. Global Public Health 5(2), 143-153.

Feierman, S., Kleinman, A., Stewart, K. A., Farmer, P. E. \& Das, V. (2010). Anthropology, knowledge-flows, and global health. Global Public Health 5(2), 122-128.

Global Forum for Health Research (GFHR) www. globalforumhealth.org/About/10-90-gap (Accessed January 21, 2010).

IJsselmuiden, C. B., Kass, N. E., Sewankambo, N. \& Lavery, J. V. (2010). Evolving values in ethics and global health research. Global Public Health 5(2), 154-163.

Kim, J., Rhatigan, J., Jain, S. \& Porter, M. E. (2010). From a declaration of values to the creation of value in global health: a report from Harvard University's Global Health Delivery Project. Global Public Health 5(2), 181-188.
McGahan, A. \& Keusch, G. T. (2010). Economic valuations in global health. Global Public Health 5(2), 136-142.

Palamountain, K., Stewart, K. A., Krauss, A., Diermeier, D. \& Kelso D. (2010). University leadership in global health and HIV/AIDS diagnostics. Global Public Health 5(2), 189-196.

Renne, E. (2006). Perspectives on polio and immunuization in northern Nigeria. Social Science and Medicine 63(7), 1857-1869.

Shapiro, K. \& Benatar, S. R. (2005). HIV prevention research and global inequality: towards improved standards of care. Journal of Medical Ethics 31, 39-47.

Stewart, K. A. \& Sewankambo, N. (2010). Okukkera Ngomuzungu (lost in translation): understanding the social value of global health research for HIV/AIDS research participants in Uganda. Global Public Health 5(2), 164-180.

Stewart, K. A., Kleinman, A. \& Keusch, G. T. (2010). Introduction: values and moral experiences in global health: bridging the local and the global. Global Public Health 5(2), 115-121.

World Bank (1993). The World Development Report 1993: Investing in Health. Washington, DC: World Bank.

World Trade Organization (WTO) www.wto.org/english/ docs_e/legal_e/27-trips_01_e.htm (Accessed January 21, 2010).

Yang, A. T., Farmer, P. E. \& McGahan, A. M. (2010) "Sustainability" in global health. Global Public Health 5(2), 129-135. 